


\section{Relações Públicas \\ História Empresarial \\ no \\ Brasil}

Paulo Nassar

- Doutor e Mestre em Ciências da Comunicação pela Escola de Comunicações e Artes da Universidade de São Paulo (ECA-USP)

- Professor e pesquisador da ECA-USP, vice-coordenador do Curso de Pós-Graduação lato sensu de Gestão Estratégica em Comunicação Organizacional e Relações Públicas (Gestcorp)

- Autor dos livros 0 que é comunicação empresarial, $A$ comunicação da pequena empresa, Tudo é comunicação, Relações públicas na construção da responsabilidade histórica e no resgate da memória institucional das organizações e organizador de Memória de empresa: história e comunicação de mãos dadas a construir o futuro das organizações, entre outros

- Diretor-presidente da Associação Brasileira de Comunicação Empresarial (Aberje)

-paulonassar@usp.br 


\section{Resumo}

A história das Relações Públicas mostra um campo em que teoria e prática estão em constante evolução. A presente pesquisa tem como objeto de estudo os vínculos entre Relações Públicas, Comunicação Organizacional e História Empresarial, e como hipótese o fato de essas imbricações se configurarem como uma nova abrangência para as Relações Públicas. Realizou-se uma pesquisa quantitativa junto a 119 organizações para testar as hipóteses ligadas às conexões entre esses campos que permitiu estabelecer características teóricas e profissionais inerentes às vinculações detectadas e comprovar a hipótese proposta.

PALAVRAS-CHAVE: RELAÇÕES PÚBLICAS - COMUNICAÇÃO ORGANIZACIONAL - HISTÓRIA EMPRESARIAL • MEMÓRIA EMPRESARIAL • MERCADO PROFISSIONAL • PESQUISA EM RELAÇÕES PÚBLICAS E COMUNICAÇÃO ORGANIZACIONAL

\section{Abstract}

The history of Public Relations shows a field where theory and practice are in constant evolution. This survey has the purpose of studying the relations between Public Relations, Organizational Communication and Business History, having established the assumption that the overlapping characterizes a new scope for Public Relations. A quantitative survey was conducted with 119 organizations with the purpose of testing the assumptions related to the connections between these fields, which enabled establishing theoretical and professional characteristics that are inherent to the detected links and confirming the assumption proposed.

KEYWORDS: PUBLIC RELATIONS • ORGANIZATIONAL COMMUNICATION • BUSINESS HISTORY • BUSINESS MEMORY - PROFESSIONAL MARKET - PUBLIC RELATIONS AND ORGANIZATION COMMUNICATION RESEARCH

\section{Resumen}

La historia de las Relaciones Públicas muestra un campo en el que la teoría y la práctica están en constante evolución. La presente investigación tiene como objeto de estudio los vínculos entre Relaciones Públicas, Comunicación Organizacional e Historia Empresarial, y como hipótesis el hecho de que esas imbricaciones se configuran como un nuevo alcance para las Relaciones Públicas. Se realizó una investigación cuantitativa con 119 organizaciones con el objetivo de probar las hipótesis vinculadas a las conexiones entre esos campos, que ha permitido establecer características teóricas y profesionales inherentes a las vinculaciones detectadas y comprobar la hipótesis propuesta.

PALABRAS CLAVE: RELACIONES PÚBLICAS - COMUNICACIÓN ORGANIZACIONAL • HISTORIA EMPRESARIAL - MEMORIA EMPRESARIAL - MERCADO PROFESIONAL • INVESTIGACIÓN EN RELACIONES PÚBLICAS Y COMUNICACIÓN ORGANIZACIONAL 
$\mathrm{E}$ sta pesquisa integra a tese de doutorado Relações Públicas e História Empresarial no Brasil: estudo de uma nova abrangência para o campo das Relações Públicas, apresentada à Escola de Comunicações e Artes da Universidade de São Paulo (ECAUSP) e defendida em 24 de agosto de 2006. A tese é composta de quatro capítulos: 1. Relações Públicas: idéias e perspectivas; 2. Relações Públicas: comentários sobre a sua trajetória no Brasil e novas perspectivas; 3. A construção da História e da Memória Empresarial como atividade de Relações Públicas; 4. Pesquisa sobre projetos de História Empresarial nas empresas brasileiras. Os capítulos 1, 2 e 3 da tese fazem uma revisão bibliográfica dos campos das Relações Públicas e da História Empresarial. O projeto contou com o patrocínio da Associação Brasileira de Comunicação Empresarial (Aberje) e foi orientado pela Profa. Dra. Margarida Maria Krohling Kunsch.

\section{Pesquisa sobre projetos de História Empresarial nas empresas brasileiras}

As empresas genuinamente brasileiras se interessam por sua história ou isto seria antes uma preocupação de empresas de capital estrangeiro? Que motivações teriam levado ou poderiam levar as empresas a se valerem de sua história? As que já institucionalizaram programas ou ações tendem a torná-los permanentes? Seus programas estão voltados para reforçar nos públicos estratégicos o sentimento de pertencimento a elas e como ferramentas de gestão do conhecimento?

Eram questões que suscitavam a formulação de outras tantas, ligadas à Comunicação Organizacional. Que espaço se reserva ou se pode reservar à Comunicação Organizacional nos trabalhos de construção da memória das empresas? A elaboração dos programas, nas empresas que já os têm, foi norteada por teorias e práticas de Relações Públicas? As Relações Públicas, por sua vez, estão incorporando ou poderiam e até mesmo deveriam incorporar conhecimentos e experiências acumulados em outras áreas, entre as quais a História Empresarial?

Algumas dessas questões foram por nós expressas na forma de hipóteses a serem comprovadas, esclarecidas ou até mesmo refutadas. A principal era que os campos das Relações Públicas e de Comunicação Organizacional ocupam um espaço estratégico no trabalho de construção da memória organizacional nas empresas brasileiras líderes em seus segmentos de atuação. Entre as hipóteses secundárias, estava a de que os trabalhos de História Empresarial desenvolvidos no campo das Relações Públicas, para lá de simples ações comemorativas, tendem a se constituir em programas perma- 
nentes, como ferramentas de gestão do conhecimento. Outra hipótese era que a preservação da história talvez não representasse uma opção ou uma prática de empresas de origem genuinamente brasileira.

De qualquer forma, tratava-se de verificar mais de perto as questões e as hipóteses formuladas, confrontando-as com as exposições teóricas que havíamos delineado. Para tanto, realizamos, em 2005, uma pesquisa empírica junto a uma amostra significativa de empresas atuantes no Brasil. Nosso principal objetivo era identificar se nelas existem conexões entre os campos das Relações Públicas e da História Empresarial. Os dados colhidos seriam tipificados, quantificados e analisados por seu enquadramento em uma linha evolutiva das Relações Públicas.

Para definir o universo de pesquisa, utilizamos como base a edição especial da Revista Exame ${ }^{1}$ relativa ao ano 2005, sobre as 500 maiores e melhores empresas do Brasil. Procedemos a um sorteio sistemático, com salto a cada cinco nomes da listagem dessa publicação, na qual as empresas estão classificadas por ordem de faturamento. Isto resultou em um quadro de cem empresas a serem pesquisadas.

Durante o processo, considerando que as instituições financeiras não constavam entre as quinhentas maiores empresas da Exame, buscamos junto à Federação Brasileira dos Bancos (Febraban) uma relação dos bancos que operam no Brasil, classificados por essa instituição pelo critério de "ativos totais", selecionando-se dentre eles os 20 maiores para contato. Além disso, incluímos na amostra 14 outras empresas que, não constantes na Exame, apareciam na quarta edição, referente a 2004, de Valor $1000^{2}$.

A metodologia empregada foi a quantitativa, com uma amostra probabilística sistemática, cuja escolha se deveu ao fato de que os elementos do estudo estavam arranjados em ordem monotônica (ranking de faturamento), tendo o salto sistemático sido, no nosso entender, mais representativo que uma amostra aleatória simples, com base na literatura por nós consultada (AAKER, KUMAR e DAY, 2001, p. 390).

Como instrumento de coleta, valemo-nos de um questionário estruturado, com perguntas fechadas, em sua maioria, e abertas. Nosso objetivo era levantar dados sobre os seguintes tópicos: definição de História Empresarial; estruturação do programa de História Empresarial; grau de importância atribuído a ele; tempo de existência; dados que se coletam; fontes de informação; produtos que se geram; área responsável; com-

1 Revista quinzenal de negócios sobre economia, finanças, gestão, tecnologia, marketing e carreira, da Editora Abril S.A. Anualmente, ela publica o guia Maiores e Melhores, escolhendo, com base em uma série de critérios econômico-financeiros, as empresas que, no ano anterior, foram destaque no país e nas suas diferentes regiões geográficas. A edição de 2005 era a 33a. da série.

2 Valor 1000 é um anuário das maiores empresas do país, por setores e regiões, publicado pelo jornal Valor Econômico, de economia, negócios e finanças, editado pela empresa Valor Econômico S.A.. 
posição da equipe; formação dos profissionais envolvidos; públicos que têm acesso ao programa; envolvimento da alta gestão; relação entre História Empresarial e planejamento; comprometimento das empresas com a história.

O questionário compunha-se de escalas nominais, escalas de avaliação verbal e de uma escala Likert ${ }^{3}$. De acordo com o autor tomado como referência sobre técnicas para medir atitudes (MATTAR, 2000, p. 92), as escalas de auto-relato são muito utilizadas, por sua facilidade de aplicação e análise. Com o uso da escala Likert foi possível testar várias afirmações, cuja base semântica eram as hipóteses do objeto de nosso estudo.

O contato com as empresas selecionadas foi estabelecido por telefone, considerada a forma mais viável, já que não se dispunha de todos os nomes dos possíveis respondentes. Os questionários foram aplicados por uma equipe de três entrevistadoras, supervisionadas por Sandra Dorgan, cuja vida profissional se desenvolveu no Instituto de Pesquisas Datafolha. A equipe de pesquisadoras foi treinada para a abordagem. O primeiro passo era identificar se as empresas tinham uma área de Comunicação Institucional, Corporativa ou de Marketing. Depois, solicitava-se um contato com o responsável pelo departamento. As empresas com as quais não se conseguiu contato foram substituídas pela seguinte da listagem da Revista Exame.

A meta original foi ultrapassada, tendo-se obtido um retorno de 119 empresas atuantes no Brasil. Foi estabelecido um compromisso com os entrevistados no sentido de compartilhar com eles as informações após a conclusão da pesquisa, o que certamente contribuiu para motivá-los a nos responder, já que se tratava de um estudo inédito. Este primeiro momento já sinalizava de alguma forma o interesse que o tema da história desperta no segmento empresarial.

\section{Os caminhos da responsabilidade histórica}

Encerrado o trabalho de campo, avaliaram-se os questionários preenchidos, codificaram-se as respostas e tabularam-se os dados. Para o processamento, valemo-nos do pacote estatístico SPSS (Statistical Package for the Social Sciences), que permite cruzar informações das diferentes variáveis de perfil (cargo do respondente, ramo de atividade, origem do capital e porte da empresa) e das respostas às questões. Com a análise dos dados, procurou-se confrontá-los com as indagações e hipóteses que pauta-

3 Escala nominal é a escala usada para classificar pessoas (sexo, classe socioeconômica, orientação no tempo etc.), identificar grupos etc.. Escala de avaliação verbal é a que se baseia em relatos orais. Escala Likert é uma escala composta por um número determinado de proposições, geralmente com cinco a sete possibilidades de respostas, variando desde discordo totalmente até concordo totalmente. Conforme o site wikipedia.org/wiki/Likert, ela tem este nome de Rensis Likert, que, em 1932, publicou uma matéria descrevendo seu uso. 
vam o nosso trabalho, para o que levamos em conta o alerta feito por Lopes (2001, p. 125), de que é necessário procurar contornar "a mera acumulação de dados e a erudição estéril”. Os principais resultados são registrados na seqüência.

\section{a. As empresas pesquisadas têm um perfil diversificado}

A pesquisa atingiu profissionais experientes, sendo que $68,2 \%$ tinham mais de 30 anos de idade. Os entrevistados eram de níveis hierárquicos distintos. Grande parte (46,2\%) se enquadrava na categoria de assessores, analistas e especialistas e mais de um terço $(36,1 \%)$ ocupava cargos de gerência e diretoria.

Tabela 1

\begin{tabular}{|l|r|r|r|r|r|}
\hline & & TOTAL & INDÚSTRIA & COMÉRCIO & SERVIÇOS \\
\hline Base & NA & 119 & 68 & 10 & 41 \\
& $\%$ & 100,0 & 100,0 & 100,0 & 100,0 \\
\hline Assessor, analista, especialista & NA & 55 & 36 & 2 & 17 \\
& $\%$ & 46,2 & 52,9 & 20,0 & 41,5 \\
\hline Coordenador, supervisor, líder & NA & 21 & 10 & 4 & 7 \\
& $\%$ & 17,6 & 14,7 & 40,0 & 17,1 \\
\hline Gerente, diretor, superintendente & NA & 43 & 22 & 4 & 17 \\
& $\%$ & 36,1 & 32,4 & 40,0 & 41,5 \\
\hline
\end{tabular}

NA - número absoluto

As indústrias compunham a maioria da amostra $(57,1 \%)$, seguidas pelas empresas de prestação de serviços $(34,5 \%)$ e comércio $(8,4 \%)$. Esta lógica amostral obedeceu à participação de cada um dos segmentos no universo da Revista Exame.

As empresas eram das mais distintas origens, com predominância das brasileiras $(55,5 \%)$. As européias somavam $20,7 \%$ e eram procedentes dos seguintes países: Alemanha, Bélgica, Espanha, França, Holanda, Inglaterra, Luxemburgo, Itália e Suécia. As de origem nos Estados Unidos representavam 15,1\%. Na categoria "outros", totalizando $8,7 \%$ da amostra, incluíam-se organizações que têm suas matrizes em países como Bermudas, Canadá, Coréia, Japão e México, além de empresas de capital multinacional (Brasil-Bélgica, França-Espanha-Luxemburgo, Brasil-Espanha e PortugalEspanha).

Quase a totalidade $(87,4 \%)$ das empresas tinha um quadro de mais de 1.000 empregados. Em 49,5\% das empresas, esse número ficava entre 1.000 e 5.000 ; em 37,8\%, acima de 5.000. Vale observar que, apesar de as empresas do segmento produtivo terem 
constituído a maioria da amostra ( $57,1 \%$, como dito acima), as de prestação de serviços (que representavam 34,5\%) tinham um número mais elevado de empregados $(46,3 \%)$ que as indústrias $(32,4 \%)$, conforme se observa na tabela abaixo.

Tabela 2. Número de funcionários versus ramo de atividade da empresa

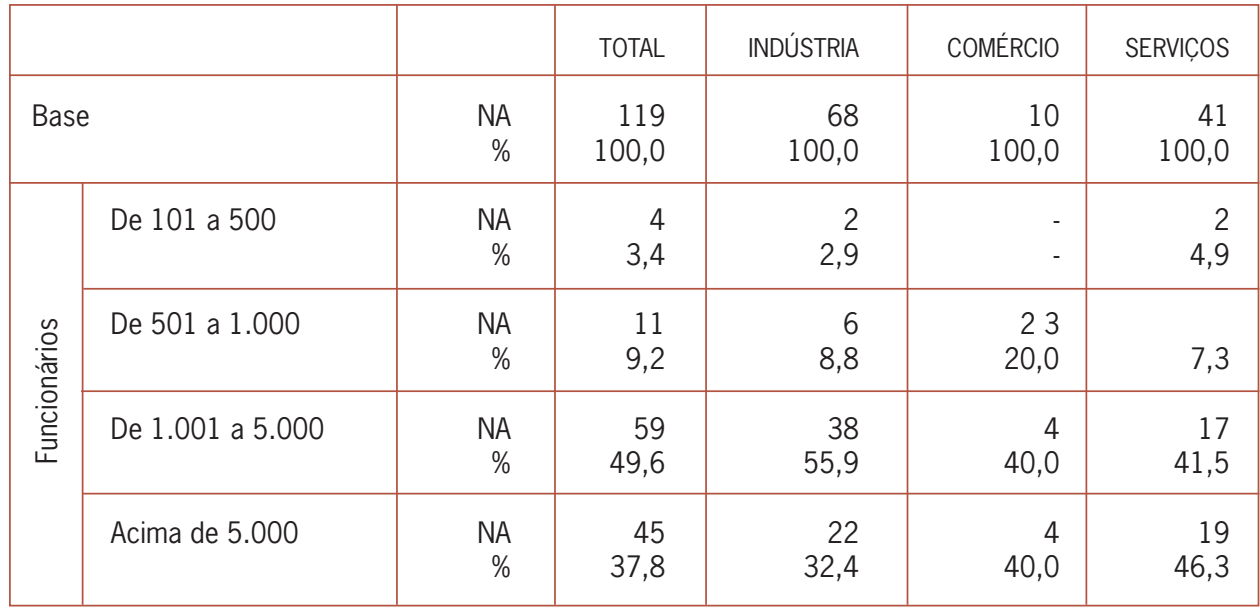

NA - número absoluto

O gráfico 1 mostra que a maioria das empresas, quando da realização da pesquisa, em 2005, mantinha atividades no Brasil havia mais de 25 anos: 84,8\%, somando-se as três categorias referentes a empresas com mais de 25 anos. A média de tempo de existência era de 58,2 anos. Eram dados importantes para nós, tendo em vista o nosso interesse em verificar como as empresas aqui atuantes tratam o tema de sua memória e de sua história.

\section{Gráfico 1. Tempo de vida da empresa}

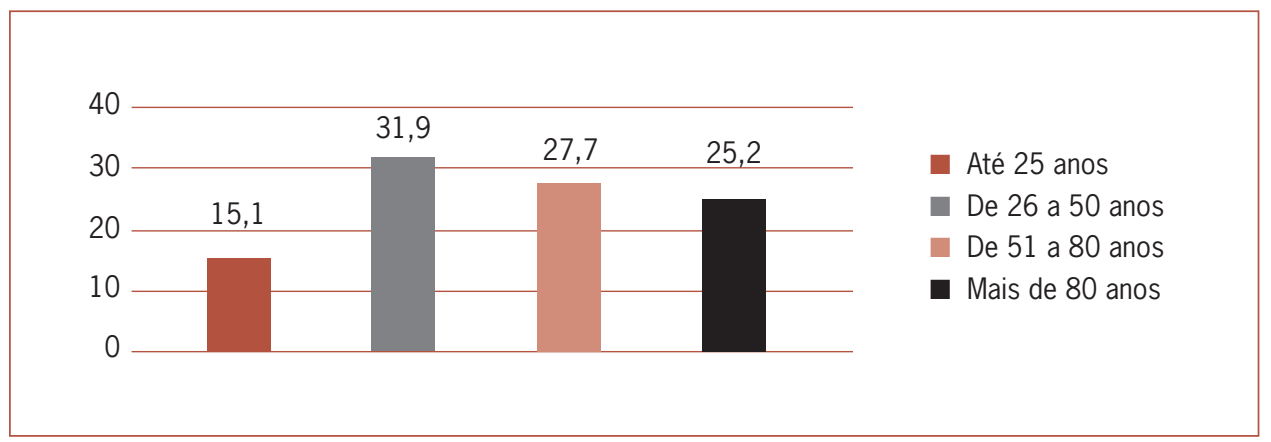




\section{b. Empresas mais antigas têm programas mais estruturados}

Iniciativas no campo da História Empresarial já eram realidade em $86,6 \%$ das empresas consultadas, de acordo com o gráfico 2 . Deste total, $49,6 \%$ já tinham programas estruturados e $37 \%$ desenvolviam ações eventuais. Em apenas 13,4\% ainda não existiam programas nem ações esporádicas.

\section{Gráfico 2. Programa de história empresarial}

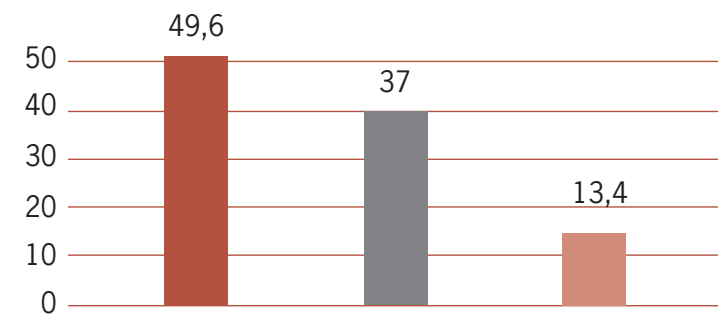

Programa estruturado

Ações eventuais

- Não existe programa

Percebe-se uma relação entre o tempo de vida da empresa e a estruturação de um programa de História Empresarial. Dentre as empresas entrevistadas, as mais antigas tinham programas mais estruturados. Das com mais de 80 anos, $60 \%$ já haviam consolidado seus programas, enquanto nas mais jovens este índice era de apenas $22,2 \%$, como demonstrado na tabela 3.

Tabela 3. Tempo de vida da empresa versus estruturação de um programa de História Empresarial - \%

\begin{tabular}{|l|c|c|c|c|c|}
\hline \multirow{2}{*}{} & \multirow{2}{*}{ Total } & \multicolumn{4}{|c|}{ Idade (em anos) } \\
\cline { 3 - 6 } & Até 25 & $\begin{array}{c}\text { de } 26 \\
\text { a } 50\end{array}$ & $\begin{array}{c}\text { de } 51 \\
\text { a } 80\end{array}$ & $\begin{array}{c}\text { Mais } \\
\text { de 80 }\end{array}$ \\
\hline $\begin{array}{l}\text { Existe programa estruturado } \\
\text { de História Empresarial }\end{array}$ & 49,6 & 22,2 & 50,0 & 54,0 & 60,0 \\
\hline $\begin{array}{l}\text { Existem accões eventuais } \\
\text { de História Empresarial }\end{array}$ & 37,0 & 50,0 & 34,2 & 39,4 & 30,0 \\
\hline $\begin{array}{l}\text { Não existem ações } \\
\text { de História Empresarial }\end{array}$ & 13,4 & 27,8 & 15,8 & 6,6 & 10,0 \\
\hline
\end{tabular}




\section{c. A importância dos programas é reconhecida pela maioria das empresas}

À indagação sobre a importância de um programa de História Empresarial, as respostas foram, em síntese, as seguintes, arroladas em três categorias principais:

- Para 95,8\% dos entrevistados, história é o resgate, a preservação e o registro da memória e cultura da empresa;

- O acúmulo de informações levantadas pode ser utilizado como ferramenta estratégica na administração, na análise do desempenho da empresa, provendo subsídios que a orientam na definição de novos rumos;

- Os programas representam uma nova forma de Comunicação Empresarial, constituindo-se em nova opção para a atuação do profissional no mercado.

Independentemente do tempo de existência da empresa, quase a totalidade $(96,7 \%)$ dos entrevistados atribuiu importância aos programas de História Empresarial, considerados "muito importantes" para 78,2\% e "importantes" para 18,5\%; apenas 3,4\% os viam como "pouco importantes".

Quanto às razões da relevância, os relatos destacaram que os registros de fatos do passado: constituem fontes de preservação da memória e subsídios para a construção da trajetória da empresa; estabelecem conexão entre o passado da organização e a compreensão da sua proposta atual e futura; contribuem para o planejamento de ações e estratégias empresariais; e fortalecem o vínculo dos públicos internos e externos com a empresa, conferindo credibilidade às relações com eles.

Questionados sobre o tempo de existência do programa, cerca de 30\% dos respondentes registram programas com mais de dez anos, como apontado no gráfico 3 . Nas empresas do ramo de serviços, $38,9 \%$ têm programas com mais de dez anos de existência e nas indústrias este índice é de $20 \%$.

\section{Gráfico 3. Tempo do Programa}

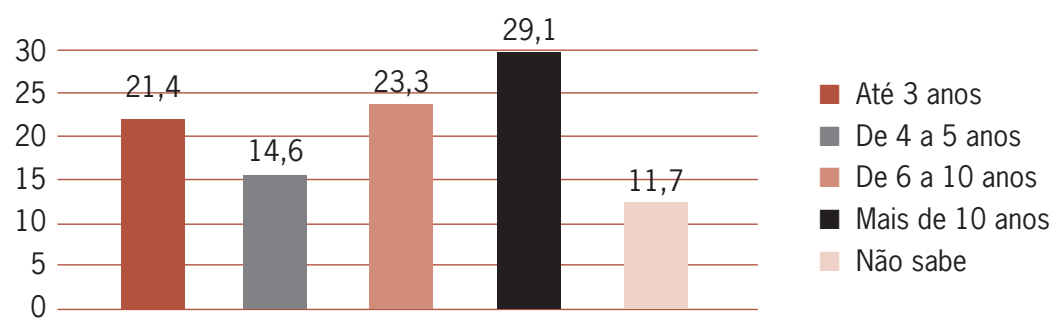




\section{d. Fotos e documentos são o material histórico mais coletado}

Das empresas que mantinham projetos de História Empresarial quando da realização da pesquisa, as dos segmentos de indústria e de serviços eram as que mais coletavam materiais, principalmente fotografias e documentos. O gráfico 4 mostra os números das empresas entrevistadas: $85,1 \%$ para fotografias e $81,2 \%$ para documentos. No caso das empresas de serviços, esses índices eram de $80,6 \%$ e $83,3 \%$, respectivamente, enquanto para os demais itens eles eram muito similares.

\section{Gráfico 4. Materiais coletados pelas empresas}

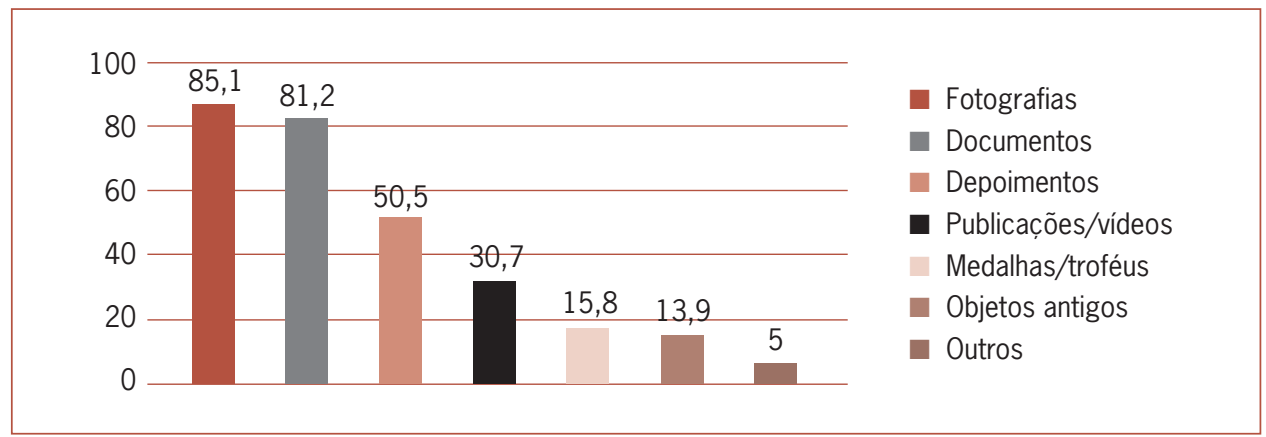

\section{e. Relatos de funcionários antigos constituem os depoimentos prioritários}

Quanto aos depoimentos como fontes para a construção da história, notou-se que há relação entre a estruturação dos programas e a prática da coleta de dados. Empresas com programas já institucionalizados buscam mais depoimentos $(56,1 \%)$ do que aquelas que só praticam ações eventuais $(43,2 \%)$.

Quando questionados sobre a origem dos depoimentos, 89,6\% dos entrevistados indicaram os relatos de antigos funcionários como fonte principal, de acordo com o gráfico 5. Esta informação sinaliza a importância da história oral, que vem carregada de sentimentos e emoções, emprestando à história da empresa um valor que vai além de sua atividade estritamente econômica.

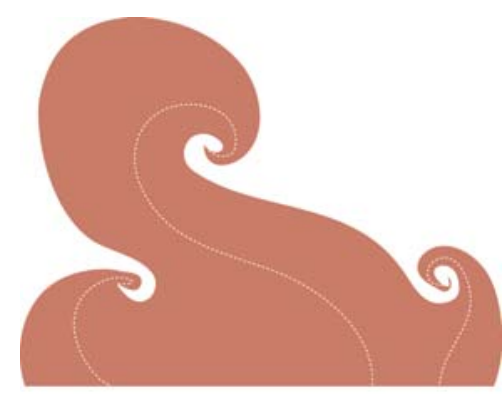




\section{Gráfico 5. Fontes dos depoimentos}

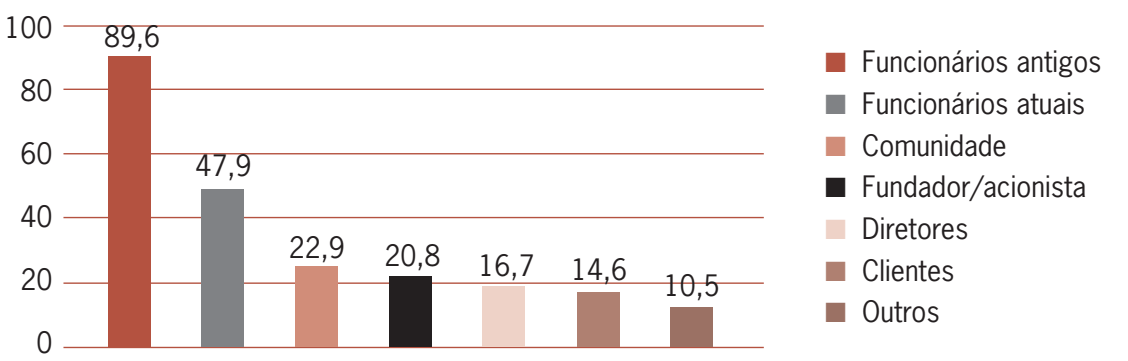

Registrou-se também uma relação entre o tempo de existência das empresas e a coleta de depoimentos de funcionários. A tabela 4 indica que, quanto mais antiga a empresa, mais os funcionários antigos são ouvidos na reconstituição de sua história.

Tabela 4. Relação entre tempo de existência das empresas e coleta de depoimentos - \%

\begin{tabular}{|l|c|c|c|c|c|}
\hline & & \multicolumn{4}{|c|}{ Idade (em anos) } \\
\cline { 2 - 6 } & Total & Até 25 & $\begin{array}{c}\text { de } 26 \\
\text { a } 50\end{array}$ & $\begin{array}{c}\text { de } 51 \\
\text { a } 80\end{array}$ & $\begin{array}{c}\text { Mais } \\
\text { de } 80\end{array}$ \\
\hline Funcionários antigos & 89,6 & 33,3 & 94,7 & 86,7 & 100,0 \\
\hline Funcionários atuais & 47,9 & 33,3 & 42,1 & 53,3 & 54,5 \\
\hline Comunidade & 22,9 & - & 26,3 & 20,0 & 27,3 \\
\hline Fundadores & 20,8 & - & 26,3 & 33,3 & - \\
\hline
\end{tabular}

\section{f. Livros, vídeos e exposições são os principais produtos de registros históricos}

O gráfico 6 indica os livros, os vídeos e as exposições como os principais produtos realizados pelos programas de história. Também chama a atenção o uso da Internet: 36,4\% dos entrevistados a citaram como veículo de divulgação da história. 


\section{Gráfico 6. Produtos realizados}

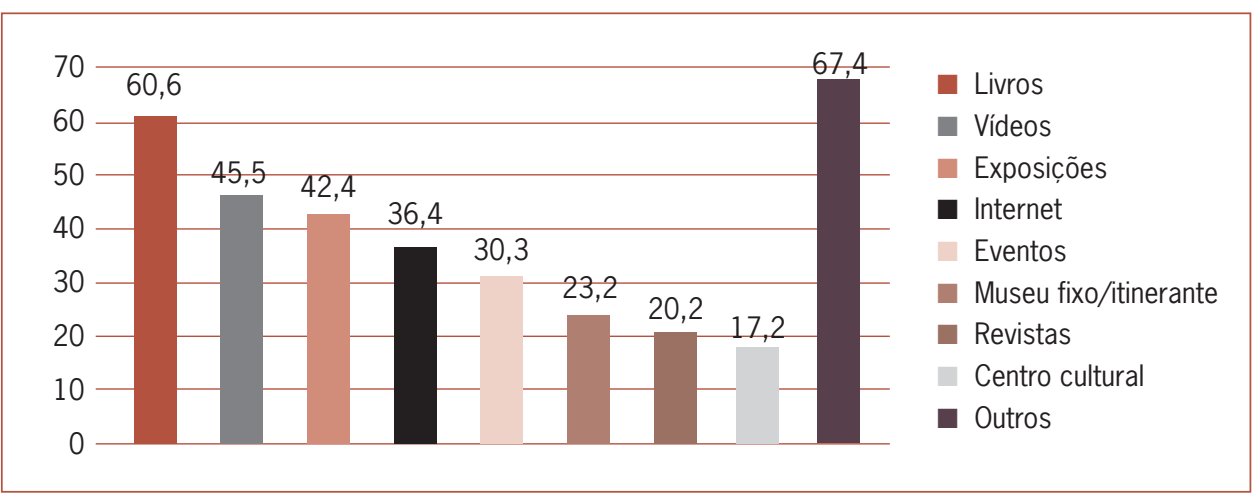

Existem, no entanto, variações significativas entre os diferentes tipos de empresas e os materiais que produzem, como se pode ver na tabela 5. No caso das exposições, por exemplo, as empresas prestadoras de serviços dão a elas um destaque maior do que as indústrias e os estabelecimentos comerciais.

Tabela 5. Materiais históricos por segmento de atividade econômica - \%

\begin{tabular}{|l|c|c|c|c|}
\hline Produtos & Total & Indústria & Comércio & Serviços \\
\hline Livros & 60,6 & 63,2 & 42,9 & 60,0 \\
\hline Vídeos & 45,5 & 54,4 & 42,9 & 31,4 \\
\hline Exposições & 42,4 & 38,6 & 28,6 & 51,4 \\
\hline Internet & 36,4 & 33,3 & 57,1 & 37,1 \\
\hline Eventos & 30,3 & 29,8 & 14,3 & 34,3 \\
\hline Museu & 23,2 & 24,6 & - & 25,7 \\
\hline
\end{tabular}

Vale um comentário sobre "outros produtos", que no gráfico 6 somam $67,4 \%$ das menções feitas pelos entrevistados. Incluem-se aí CD-ROMs, galerias, memorial permanente, intranet, folders, murais, banco de dados, acervo de fotos e peças, áudio, palestras, publicações, brindes, manuais, DVDs, ações sociais, biblioteca, selo comemorativo, atlas, cursos e álbuns como alguns exemplos. Isso pode indicar que as empresas vêm buscando meios alternativos para registrar e divulgar sua história. 


\section{g. Profissionais de comunicação lideram os projetos de História}

Os programas de História das empresas entrevistadas achavam-se fortemente associados à área de Comunicação Corporativa, como mostra o gráfico 7, embora em mais de um terço delas fosse comum o envolvimento de mais de uma área. Algumas empresas se valiam de equipes multidisciplinares, atuantes na forma de comitês.

\section{Gráfico 7. Área responsável}

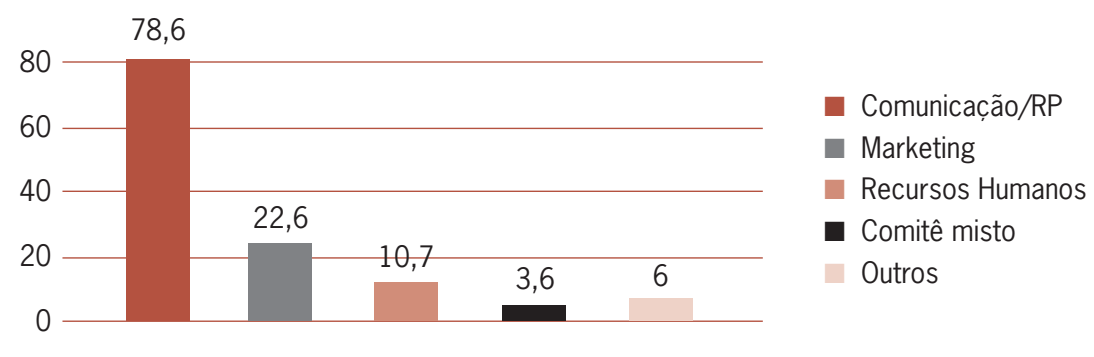

Das empresas do segmento industrial, $70,9 \%$ dos entrevistados apontaram como preferencial o trabalho realizado conjuntamente por equipe interna e externa. No caso das prestadoras de serviços, esse índice era de $66,7 \%$.

É interessante notar que, até mesmo nas empresas que mantinham um programa de História Empresarial estruturado, predominavam as equipes que trabalhavam em conjunto $(81,4 \%)$, o que sugere uma necessidade de se dispor de profissionais especializados. No caso das empresas que realizam ações eventuais, esse percentual era menor $(56,8 \%)$, como se pode conferir na tabela 6 .

Tabela 6. Coleta de materiais em empresas com programas estruturados e em empresas com ações eventuais - \%

\begin{tabular}{|l|c|c|c|}
\hline & Total & $\begin{array}{c}\text { Programas } \\
\text { estruturados }\end{array}$ & Ações eventuais \\
\hline Equipe interna & 28,2 & 16,9 & 43,2 \\
\hline Empresa especializada & 1,0 & 1,7 & - \\
\hline Trabalho conjunto & 70,0 & 81,4 & 56,8 \\
\hline
\end{tabular}




\section{h. Relações-públicas, os profissionais mais presentes}

No gráfico 8, vê-se que, nas empresas entrevistadas, $24,5 \%$ dos profissionais responsáveis por projetos de História Empresarial eram graduados em Relações Públicas, seguidos pelos jornalistas $(19,6 \%)$ e por profissionais de Marketing (11,8\%). Essa informação sinaliza que os programas de História Empresarial, por lidarem diretamente com a imagem institucional da organização, contemplam as funções atribuídas à Comunicação, especialmente às Relações Públicas. No entanto, esta é uma área que chamamos de "mestiça", reunindo até mesmo pedagogos, antropólogos, musicólogos, arquitetos, cientistas sociais, advogados, psicólogos e economistas, que também estão representados na pesquisa, na categoria "outros", com 13,9\% da amostra.

\section{Gráfico 8. Formação do profissional interno}

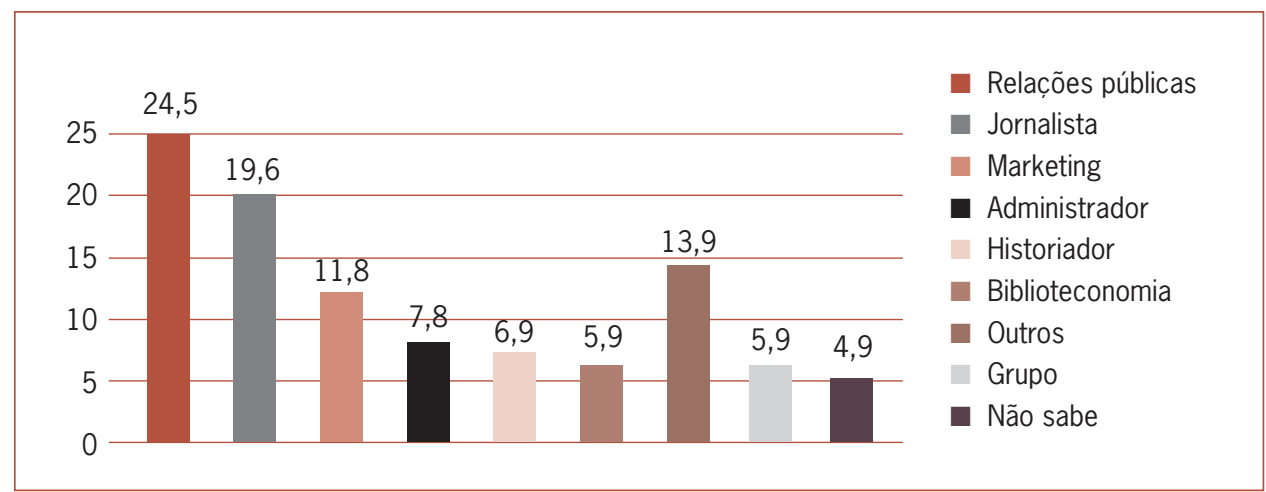

\section{i. A participação dos historiadores na construção dos programas}

Quando os profissionais responsáveis pelo programa de História Empresarial são contratados, isto é, não integram a equipe interna da empresa, os historiadores lideram o ranking, com $32,4 \%$ da amostra, seguidos pelos jornalistas $(17,6 \%)$ e, logo depois, pelos publicitários $(12,2 \%)$, de acordo com o gráfico 9 . Novamente, as profissões de humanidades, além de outras especializações da Comunicação, comparecem, reunidas, com 9,7\% da amostra: Relações Públicas, Biblioteconomia, Antropologia, Letras, Editoração e Ciências Sociais. Comparando os gráficos 8 e 9, é possível identificar uma tendência à formação de equipes mistas e multidisciplinares para o desenvolvimento de projetos de História Empresarial. 


\section{Gráfico 9. Formação do profissional externo}

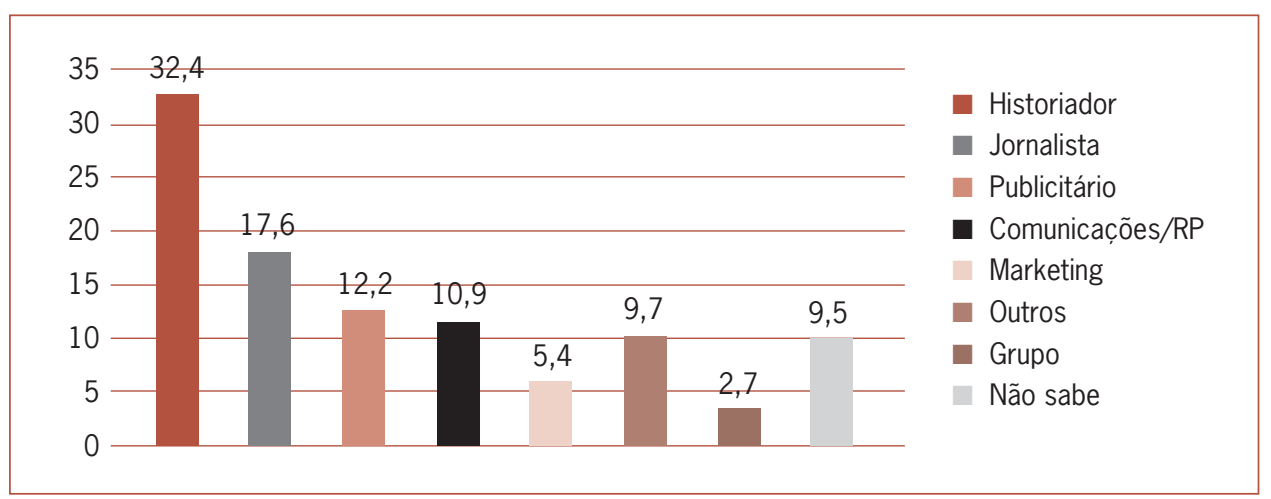

\section{j. Equipes internas selecionam as informações do acervo histórico}

A responsabilidade de selecionar as informações que integrarão o acervo histórico das empresas é confiada à equipe interna pela maioria das empresas entrevistadas $(56,3 \%)$. Em 35,9\% dos casos, esse trabalho é realizado conjuntamente com a equipe externa. Os índices se mantêm nesse patamar tanto no setor industrial quanto nos segmentos comercial e de serviços. Além destes, em 4,9\% das empresas o responsável pela seleção é o coordenador, a empresa contratada em 1,9\% dos casos e os fundadores, com $1 \%$ de citação.

\section{k. Programas de História Empresarial têm vida longa e futuro promissor}

Questionamos os entrevistados sobre o grau de concordância com algumas frases, todas elas hipóteses sobre programas de História Empresarial. Como se pode ver no gráfico 10, a concordância ou discordância se deu num bloco bem homogêneo. A única hipótese que dividiu os entrevistados foi sobre o uso que as empresas fazem dos projetos de História Empresarial como instrumento de Marketing: 51,4\% concordaram com esta hipótese e $47,6 \%$ discordaram dela. Por outro lado, 97,1\% discordaram da afirmação de que a História Empresarial é uma moda que vai passar. Na percepção de $88,3 \%$ da amostra, os programas de história demonstram o comprometimento das empresas com o país. E $89,3 \%$ também concordaram com a ponderação de que preservar a história das empresas é uma ação de responsabilidade social.

Solicitados a corroborar ou não a afirmação de que os trabalhos empresariais não precisam ter compromisso com a autenticidade dos fatos, 97, 1\% discordaram. E 87,4\% também discordaram totalmente de que se deve valorizar a história apenas em momentos festivos. Quanto à afirmação de que o sucesso do programa de História depende do apoio da alta gestão, $98,1 \%$ concordaram inteiramente. O fato de $96,2 \%$ terem concordado com a ponderação de que o conhecimento da história pode ser útil no planejamento de negócios confirma a valorização dos programas de História Empresarial. 


\section{Gráfico 10. Hipóteses sobre os programas de história}

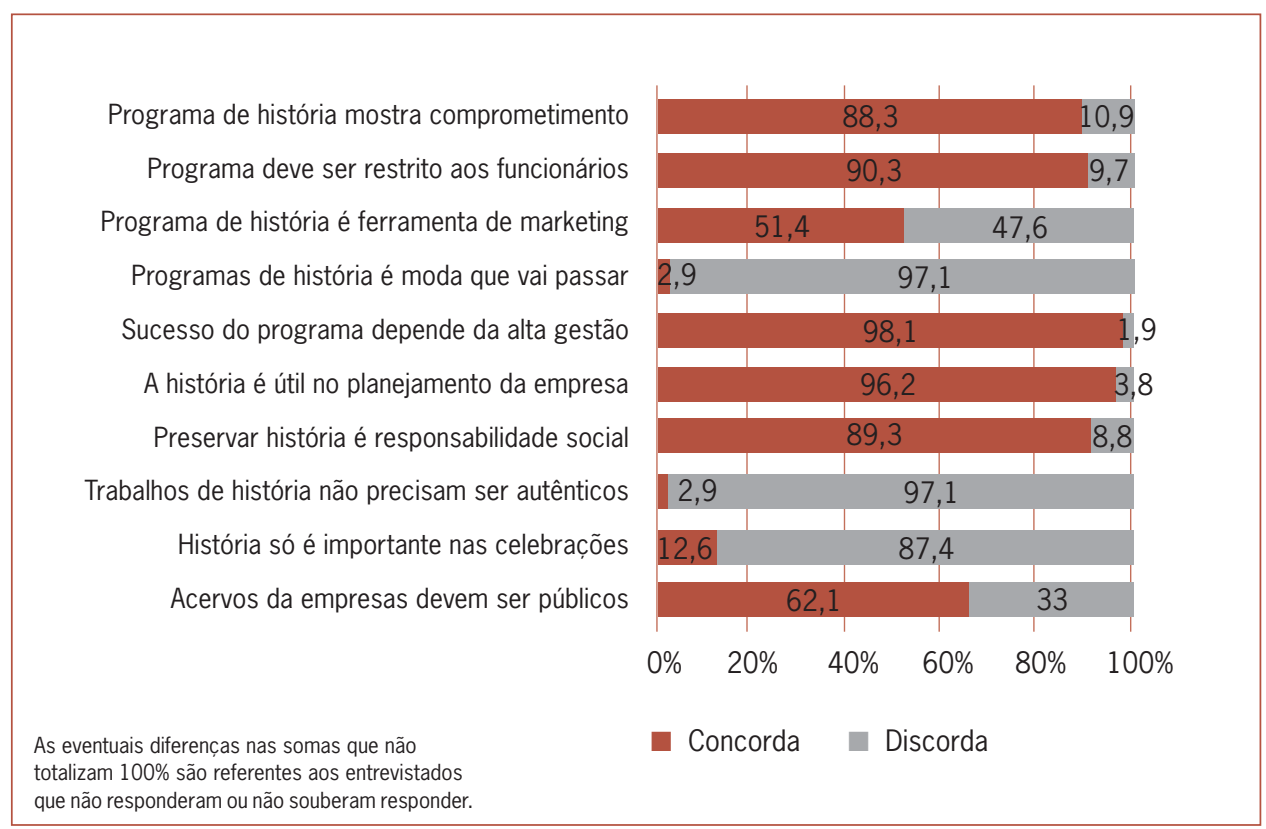

E, finalmente, quando indagados sobre se concordavam ou não em tornar públicos os acervos da empresa, $62,1 \%$ disseram que concordavam. É curioso notar que, mesmo acreditando que a História Empresarial é importante para o país, uma parcela significativa dos entrevistados deseja que a informação fique restrita ao âmbito interno. Isto expressa uma divergência em relação à importância de tornar públicos acervos históricos privados. Outro dado que embasa essa divergência foi revelado pela discordância de 90,3\% quanto à opinião de que programas de história devem ficar restritos aos funcionários da empresa.

\section{Disponibilização dos acervos históricos}

Das empresas que tinham programa de História Empresarial quando da realização da pesquisa, $89 \%$ disponibilizavam seu acervo histórico para os empregados, como mostra o gráfico 11. A comunidade e o público em geral também tinham acesso às informações $(51 \%)$, incluindo os clientes $(23 \%)$, a imprensa (15\%), familiares dos empregados $(14 \%)$ e estudantes ( $8 \%)$. 


\section{Gráfico 11. Públicos que têm acesso ao acervo}

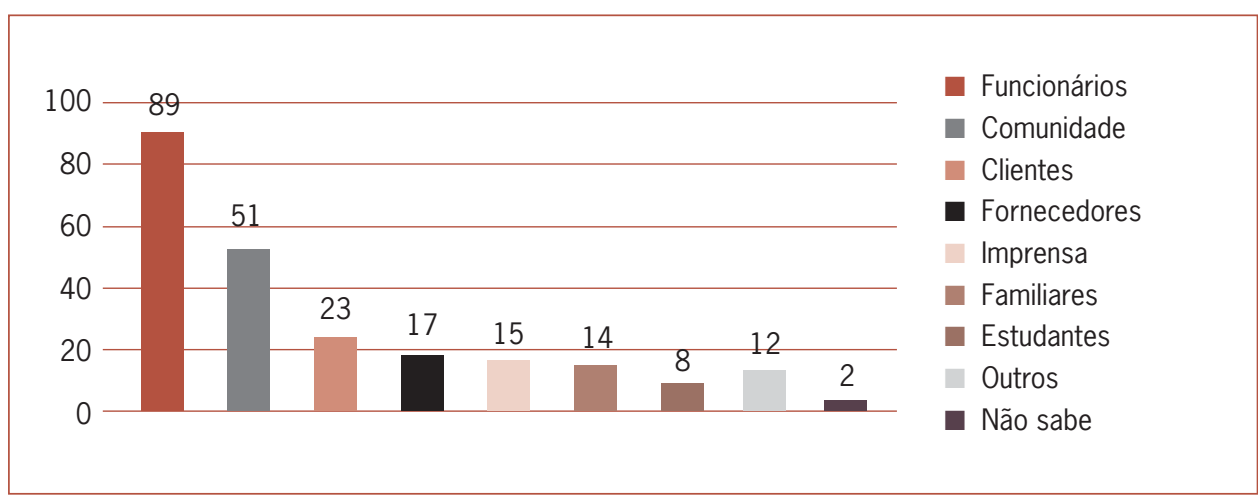

O amplo acesso disponibilizado pelas empresas indica que há interesse estratégico na divulgação da História Empresarial, pois, de acordo com 89,3\% dos participantes da pesquisa, preservar a história das empresas é uma ação de responsabilidade social. Outro dado que confirma o valor estratégico da História Empresarial é a concordância de $96,2 \%$ com a afirmação de que o conhecimento da história pode ser útil no planejamento dos negócios.

\section{Perspectivas para as Relações Públicas e para a Comunicação Organizacional}

A pesquisa realizada nos permitiu tirar algumas conclusões que responderam a indagações que tínhamos em mente e, por outro lado, confirmaram, esclareceram ou descaracterizaram parcialmente as hipóteses que havíamos formulado.

1. A pesquisa realizada sinalizou que a área de História Empresarial está se estruturando nas maiores organizações do país. Como estas lançam tendências de gestão e Comunicação, espera-se que, no médio prazo, a valorização da História Empresarial passe a ser reconhecida por outros segmentos.

2. Os campos das Relações Públicas e da Comunicação Corporativa estão ampliando seus espaços nas organizações, sendo a História Empresarial mais uma área de atividade. De acordo com os dados coletados e sinalizados no gráfico 8 , vêse que, nas empresas entrevistadas, $24,5 \%$ dos profissionais responsáveis por projetos de História Empresarial eram graduados em Relações Públicas. Além de mobilizar profissionais de Relações Públicas e Comunicação, estes programas trazem para a esfera privada profissionais mais ligados à prática pública de resgate e manutenção histórica - os historiadores.

3. A História Empresarial configura-se como um novo campo de atividades para os profissionais de Relações Públicas, pois serão eles, como estrategistas, que 
irão registrar os relacionamentos da empresa com seus públicos. Muito embora seja uma área onde vários profissionais especializados participem, será o gestor de Relações Públicas e de Comunicação Organizacional o responsável por esta atividade.

4. Nas grandes empresas pesquisadas, muito embora $86,6 \%$ já tenham desenvolvido iniciativas relacionadas com a História Empresarial, apenas metade (49,6\%) delas tinha projetos estruturados. Como a maioria dos profissionais acreditava que a alta gestão deve estar envolvida para o sucesso do programa, nota-se que, mesmo nas grandes organizações, há um longo caminho a percorrer.

5. Os principais trabalhos desenvolvidos por estes profissionais se traduzem em livros, vídeos, exposições e outros produtos. Há sinais, no entanto, de que, nas empresas com programas mais estruturados, estão em andamento produtos sofisticados, tais como museus permanentes e história contada.

6. Quando o resgate histórico é feito por meio do registro de depoimentos, são os funcionários antigos a fonte de informação mais utilizada. Esta história oral, passada por meio de depoimentos gravados em áudio e vídeo, é um rico material, já que, além do registro do fato, vem carregado de emoção e credibilidade.

7. A importância dos projetos de História nas empresas é reconhecida por quase todos os pesquisados, pois, além de tudo, eles também funcionam como ferramenta de gestão. A análise do passado ajuda a projetar o futuro e estas informações podem, quando sistematizadas em bancos de dados, servir como instrumento de inteligência competitiva.

8. O Brasil não é um país que investe sistematicamente na preservação da História. No entanto, foi uma grata surpresa verificar que, dentre as empresas com programas estruturados de preservação histórica, 57,6\% são brasileiras.

9. Tudo indica que o cuidado com a História Empresarial é uma tendência e não uma moda passageira. O grande desafio é identificar se a motivação que leva as empresas ao resgate da história é genuína ou se representa mais um nicho a ser explorado pelo Marketing.

As conclusões da pesquisa só reforçam as reflexões apresentadas até aqui e também interações entre os pensamentos e as práticas de inúmeras disciplinas presentes no cotidiano das empresas e instituições.

Os principais dados levantados e as tendências apuradas pela pesquisa empírica apontam para um trabalho conjunto entre os campos das Relações Públicas e da História. Abre-se, assim, um espaço de trabalho qualificado para os pesquisadores e profissionais das áreas de Relações Públicas, Comunicação e História, numa aproximação entre disciplinas que promovem a ciência e o trabalho, a teoria e a prática, alargando a abrangência desses campos do conhecimento e mostrando que é possível que se unam sem perder suas identidades originais. 
RELAÇÕES PÚBLICAS E HISTÓRIA EMPRESARIAL NO BRASIL • PAULO NASSAR

\section{Bibliografia}

AAKER, David A.; KUMAR, V.; DAY, George S.. Pesquisa de marketing. São Paulo: Atlas, 2001.

GIL, Antonio Carlos. Como elaborar projetos de pesquisa. São Paulo: Atlas, 2002.

LOPES, Maria Immacolata Vassallo de. Pesquisa em comunicação: formulação de um modelo metodológico. São Paulo: Loyola, 1990.

MATTAR, Fauze N. Pesquisa de marketing. Edição compacta. 2.ed. São Paulo: Atlas, 2000.

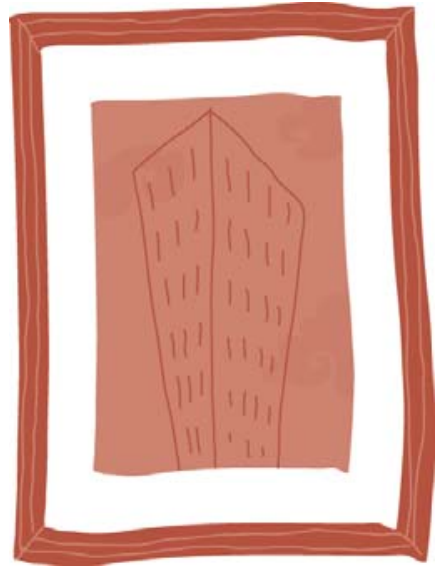

ANO 3 • NÚMERO $5 \cdot 2^{\circ}$ SEMESTRE DE 2006 • organicom • 173 


\section{ANEXO}

\section{QUESTIONÁRIO}

\section{Perguntas relacionadas às hipóteses}

Hipótese principal

Os campos das Relações Públicas e de Comunicação Organizacional ocupam um espaço estratégico no trabalho de construção da memória organizacional nas empresas brasileiras líderes em seus segmentos de atuação.

Perguntas cruzadas com a origem e os ramos de atividade da empresa.

Qual é a área responsável pelos programas de memória empresarial?

\begin{tabular}{|l|}
\hline 1 Comunicação \\
\hline 2. Relações Públicas \\
\hline 3. Marketing \\
\hline 4. Recursos Humanos \\
\hline 5. Presidência \\
\hline 6. Comitê de várias áreas \\
\hline 7. Outra área. Qual? \\
\hline 8. Não sei \\
\hline
\end{tabular}

Analisando as frases que vou citar, qual delas melhor reflete a experiência que esta empresa tem com o programa de memória empresarial?

1. Temos uma equipe interna que realiza o trabalho

2. Contratamos uma empresa especializada

3. Fazemos um trabalho conjunto, interno e externo

4. Outra forma (anote)

5. Não sabe/não respondeu 
Qual a formação do profissional responsável pelo projeto de História?

\begin{tabular}{|ll|}
\hline Profissional interno & Profissional externo \\
\hline 1 Historiador & 1 Historiador \\
\hline 2. Relações Públicas & 2. Relações Públicas \\
\hline 3. Marketing & 3. Marketing \\
\hline 4. Publicitário & 4. Publicitário \\
\hline 5. Jornalista & 5. Jornalista \\
\hline 6. Outro. Qual? & 6. Outro. Qual? \\
\hline
\end{tabular}

Gostaria de saber qual o departamento responsável pelas ações de Comunicação Corporativa da empresa?

\begin{tabular}{|l|}
\hline 1. Diretoria de Comunicação/Relações Públicas \\
\hline 2. Diretoria de Marketing \\
\hline 3. Diretoria de Recursos Humanos \\
\hline 4. Diretoria Administrativa \\
\hline 5. Outra diretoria. Qual? \\
\hline 6. Não sabe/não respondeu
\end{tabular}

\section{Hipóteses secundárias}

Os trabalhos de História Empresarial desenvolvidos no campo das Relações Públicas, para lá de simples ações comemorativas, tendem a se constituir em programas permanentes, como ferramentas de gestão do conhecimento.

A preservação da história talvez não representasse uma opção ou uma prática de empresas de origem genuinamente brasileira.

Cruzamento das questões com a origem da empresa.

Pensando em programas de História Empresarial, você diria que na sua empresa:

\begin{tabular}{|l|}
\hline 1. Existe um programa estruturado de História Empresarial \\
\hline 2. Existem ações eventuais de História Empresarial \\
\hline 3. Não existem ações de História Empresarial \\
\hline 4. Não sei
\end{tabular}


Há quantos anos existe o programa de História Empresarial nesta empresa? Anote:

\begin{tabular}{|l|}
\hline 1. Menos de 1 ano \\
\hline 2. Entre 1 e 3 anos \\
\hline 3. Entre 3 e 5 anos \\
\hline 4. Entre 5 e 10 anos \\
\hline 5. Mais de 10 anos \\
\hline 6. Não sei \\
\hline
\end{tabular}

O que exatamente o Programa de Memória Empresarial coleta?

\begin{tabular}{|l|}
\hline 1 Documentos \\
\hline 2. Fotografias \\
\hline 3. Medalhas/troféus \\
\hline 4. Depoimentos \\
\hline 5. Outros. O quê? \\
\hline
\end{tabular}

Quem fornece os depoimentos que são coletados?

\begin{tabular}{|l|}
\hline 1. Funcionários antigos \\
\hline 2. Funcionários atuais \\
\hline 3. Diretores \\
\hline 4. Comunidade \\
\hline 5. Clientes \\
\hline 6. Outros. Quais? \\
\hline
\end{tabular}

Quais produtos do programa de memória já foram realizados? (múltiplas respostas)

\begin{tabular}{|l|}
\hline 1. Livros \\
\hline 2. Vídeos \\
\hline 3. Museus \\
\hline 4. Internet \\
\hline 5. Centro de referência virtual \\
\hline 5. Exposições \\
\hline 6. Eventos \\
\hline 7. Revistas \\
\hline 8. CD ROM \\
\hline 9. Áudio \\
\hline 10. Outros. Quais? \\
\hline
\end{tabular}


Quais são os públicos que têm acesso ao acervo?

\begin{tabular}{|l|}
\hline 1. Funcionários da empresa \\
\hline 2. Familiares dos funcionários \\
\hline 3. Clientes \\
\hline 4. Fornecedores \\
\hline 5. Imprensa \\
\hline 6. Público geral/comunidade \\
\hline 7. Não sabe/Não respondeu \\
\hline 8. Outros. Quais? \\
\hline
\end{tabular}

Vou citar algumas frases e gostaria de saber se você concorda ou discorda totalmente ou parcialmente:

\begin{tabular}{|c|c|c|c|c|c|c|}
\hline & $\begin{array}{l}\text { Discorda } \\
\text { totalmente }\end{array}$ & $\begin{array}{l}\text { Discorda } \\
\text { parcialmente }\end{array}$ & $\begin{array}{l}\text { Não concorda, } \\
\text { nem discorda }\end{array}$ & $\begin{array}{l}\text { Concorda } \\
\text { parcialmente }\end{array}$ & $\begin{array}{l}\text { Concorda } \\
\text { totalmente }\end{array}$ & NS/NR \\
\hline $\begin{array}{l}\text { 1. O sucesso do programa } \\
\text { de memória depende } \\
\text { do apoio da alta gestão }\end{array}$ & & & & & & \\
\hline $\begin{array}{l}\text { 2. O programa de memória } \\
\text { deve ser restrito aos } \\
\text { funcionários da empresa }\end{array}$ & & & & & & \\
\hline $\begin{array}{l}\text { 3. Memória empresarial } \\
\text { é uma moda que } \\
\text { vai passar }\end{array}$ & & & & & & \\
\hline $\begin{array}{l}\text { 4. As empresas fazem } \\
\text { projeto de memória para } \\
\text { usar como instrumento } \\
\text { de Marketing }\end{array}$ & & & & & & \\
\hline $\begin{array}{l}\text { 5. Preservar a memória } \\
\text { das empresas é uma ação } \\
\text { de responsabilidade social }\end{array}$ & & & & & & \\
\hline $\begin{array}{l}\text { 6. Os acervos de memórias } \\
\text { empresariais deveriam } \\
\text { ser patrimônio público }\end{array}$ & & & & & & \\
\hline $\begin{array}{l}\text { 7. A memória das empresas } \\
\text { só é importante nos } \\
\text { momentos de celebração }\end{array}$ & & & & & & \\
\hline $\begin{array}{l}\text { 8. Trabalhos de História } \\
\text { Empresarial não necessitam } \\
\text { ter compromisso com } \\
\text { a autenticidade dos fatos }\end{array}$ & & & & & & \\
\hline $\begin{array}{l}\text { 9. O conhecimento da } \\
\text { história pode ser útil no } \\
\text { planejamento dos negócios }\end{array}$ & & & & & & \\
\hline $\begin{array}{l}\text { 10. Os programas de memória } \\
\text { demonstram o comprometimento } \\
\text { das empresas com o país }\end{array}$ & & & & & & \\
\hline
\end{tabular}

